\title{
Study of the Relationship between Abdominal Obesity and Micro-Albuminuria in Elderly
}

\author{
Mahmoud $\mathrm{AH}^{*}$ and Taha HM
}

Department of Geriatrics and Gerontology, Faculty of Medicine, Ain Shams University, Cairo, Egypt

*Corresponding author: Mahmoud AH, Department of Geriatrics and Gerontology, Faculty of Medicine, Ain Shams University, Cairo, Egypt, Tel: +966571435305, E-mail: amira_mahmoud93@ yahoo.com

Citation: Mahmoud AH, Taha HM (2015) Study of the Relationship between Abdominal Obesity and Micro-Albuminuria in Elderly. J Obes Overweig 1(2): 202. doi: 10.15744/2455-7633.1.202

Received Date: July 09, 2015 Accepted Date: August 24, 2015 Published Date: August 26, 2015

\begin{abstract}
Background: Obesity increases the risk for variety of diseases which in turn, decreases the overall lifespan in both men and women. Though the cardiovascular risks of obesity are widely acknowledged, less often identified is the relationship between obesity and renal function.
\end{abstract}

Aim: To study the relationship between abdominal obesity and micro-albuminuria in elderly subjects.

Methods: A cross sectional study was conducted on 200 elderly subjects, aged $\geq 60$ years. Subjects were recruited from both Geriatrics and Gerontology department and Internal medicine at Ain Shams University hospital, Cairo, Egypt. All patients had anthropometric measurements done including weight, height, body mass index, waist circumference, hip circumference and waist hip ratio, also assessment of blood pressure and albumin/creatinine ratio in urine.

Results: Mean age of participants was $74.96 \pm 5.603$ years. Mean waist circumference in whole sample measured $96.78 \pm 16.85$, mean hip circumference was $106.31 \pm 19.24$, mean waist hip ratio measured $0.91 \pm 0.09$ and mean body mass index was $27.83 \pm 9.8$. All of waist circumference, waist hip ratio, systolic blood pressure, hypertension, diabetes mellitus, ischemic heart disease, renal disease were significantly related to micro-albuminuria. Also, fasting blood sugar, serum triglycerides and renal functions were related to micro-albuminuria, meanwhile on multivariate analysis abdominal obesity as measured by waist hip ratio was the strongest variable correlated with micro-albuminuria in elderly subjects in the whole sample.

Conclusion: Abdominal obesity is strongly associated with micro-albuminuria in Egyptian elderly.

Keywords: Abdominal obesity; Anthropometric measures; Elderly; Microalbuminuria

Abbreviations: ESRD: End-Stage Renal Disease; MA: Micro-albuminuria; WC: Waist Circumference; HC: Hip Circumference; WHR: Waist / Hip ratio; ACR: Albumin/Creatinine Ratio

\section{Introduction}

A very high rate of obesity was reported among Egyptians [1]. Obesity, both directly and indirectly, increases the risk for a variety of disease conditions including diabetes, hypertension, liver disease, and certain cancers, which in turn, decreases the overall lifespan in both men and women [2].

Proteinuria was identified as a significant predictor of end-stage renal disease (ESRD) in a mass screening of volunteers [3] and reported as a risk factor for cardiovascular or total mortality $[4,5]$.

Micro-albuminuria (MA) is defined when urinary albumin excretion level is between 30-300 mg/day [6]. MA is not only a predictor of nephropathy in diabetic patients [7] but is also associated with renal functional abnormalities in non-diabetic subjects [8].

The important role abdominal versus peripheral fat distribution on urinary albumin excretion has been highlighted by various authors [9]. Waist circumference which measures central obesity reflects metabolically active visceral fat [10,11], whereas Body mass index does not account for the wide variations in body fat distribution and has considerable limitations in prediction of intra-abdominal fat accumulation [12]. Waist hip ratio is reported to be a more efficient predictor of mortality in older people [13] and also a better predictor of cardiovascular disease [14] than waist circumference or body mass index.

Abdominal obesity symbolizes a key component of the metabolic syndrome. The fundamental component that associates abdominal obesity to other features of the metabolic syndrome and end-organ damage are apparently due to elevated insulin levels, peripheral tissue resistance to the insulin-sensitizing action of leptin and increased macrophage infiltration in fat tissues with concomitant release of pro-inflammatory cytokines [15,16]. This further decreases the functional integrity of the renal endothelial wall and lead to micro-albuminuria [9]. 
Though the cardiovascular risks of obesity are widely acknowledged, less often identified is the relationship between obesity and renal function, also studies addressing old age group are lacking. So, this study is being undertaken to determine relationship between abdominal obesity and micro-albuminuria in elderly.

\section{Subjects and Methods}

A cross sectional study was conducted on two hundred elderly subjects during the period from (January 2012 to December 2012). All patients were 60 years old and over, both males and females were included.

Mean age of participants was $74.96 \pm 5.603$ years, males represented $52 \%$ and females represented $48 \%$.

Participants were recruited from both Geriatrics and Gerontology department and Internal medicine department at Ain Shams University hospital in Cairo, Egypt.

All subjects had comprehensive geriatric assessment and cognitive assessment done, also anthropometric measurements and laboratorial measurements of fasting blood sugar (FBS), lipid profile (Total cholesterol, LDL, HDL, serum triglycerides), kidney functions (Blood urea nitrogen, serum creatinine) and assessment of albumin / creatinine ratio in urine.

As regards anthropometric measurements, waist circumference (WC) and hip circumference (HC) were measured according to the World Health Organisation's data gathering protocol [17], the waist circumference was measured at the midpoint between the lower margin of the last palpable rib and the top of the iliac crest, using a stretch-resistant tape that provides a constant $100 \mathrm{~g}$ tension. Hip circumference was measured around the widest portion of the buttocks, with the tape parallel to the floor [18]. WC and $\mathrm{HC}$ measurements were expressed in centimeters and Waist / Hip ratio (WHR) was calculated.

BMI was calculated by dividing the body weight (in kilograms) by square of height (in meters).

WHO STEPS states that abdominal obesity is defined as a WHR above 0.90 for males and above 0.86 for females, or BMI above $30.0[18]$.

As regards ACR, early morning urine samples were obtained, the amount of albumin in the sample was compared against its concentration of creatinine, to compensate for variations in urine concentration in spot-check samples [19]. Micro-albuminuria is defined as ACR $\geq 3.5 \mathrm{mg} / \mathrm{mmol}$ (female) or $\geq 2.5 \mathrm{mg} / \mathrm{mmol}$ (male) [20].

NICE recommends that ACR should be used in preference to other tests of proteinuria, because it offers greater sensitivity for the detection of lower, but clinically significant, levels of proteinuria [21].

As regards Co-morbidities among subjects, renal insufficiency was defined as admission values for creatinine $>1.4 \mathrm{mg} / \mathrm{dl}$, Diabetes Milletus was defined by fasting blood glucose level $\geq 126 \mathrm{mg} / \mathrm{dl}$ or 2 hours postprandial plasma glucose $\geq 200 \mathrm{mg} / \mathrm{dl}$ and Hypertension as systolic blood pressure $\geq 140$ or diastolic blood pressure $\geq 90$.

\section{Statistical methods}

The collected data were coded, tabulated, revised and statistical analyzed using SPSS program (version 20). Descriptive statistics were done using mean and standard deviation for numerical parametric data and by number and percentage for categorical data. Statistical analysis was done for quantitative variables by using independent $t$-test in case of two independent groups, paired t-test in related samples with parametric data. Stepwise linear regression analysis used for significant clinical variables. The level of significance was taken at $\mathrm{P}$ value $<0.05$.

\section{Results}

Analysis of baseline socio-demographic characters of subjects showed that mean age of participants was $74.9 \pm 5.6$ years, males represented $52 \%$ of subjects and females represented $48 \%$.

Distributions of co-morbidities showed that hypertension followed by diabetes were the most common present co-morbidities among participants (Table 1).

\begin{tabular}{|c|c|c|}
\hline & N & \% \\
\hline DM & 84 & 42 \\
\hline HTN & 100 & 50 \\
\hline COPD & 76 & 38 \\
\hline ISHD & 80 & 40 \\
\hline CHF & 32 & 16 \\
\hline CLD & 24 & 12 \\
\hline Renal disease & 60 & 30 \\
\hline Old CVS & 32 & 16 \\
\hline Dementia & 8 & 4 \\
\hline
\end{tabular}

Diabetes mellitus (DM), Hypertension (HTN), Chronic obstructive pulmonary disease (COPD), Ischemic heart disease (ISHD), Congestive heart failure (CHF), Chronic liver disease (CLD), Cerebrovascular disease (CVS)

Table 1: Distribution of co-morbidities among participants 
Distribution of anthropometric measurements showed that mean WC measured $96.7 \pm 16.8$, mean HC measured 106.3 \pm 19.2 , mean WHR measured $0.91 \pm 0.09$ among subjects and mean BMI was $27.8 \pm 9.8$.

Relation of age, anthropometric measurements, blood pressure and laboratory measurements (FBS, renal function tests, lipid profile) with MA among subjects is shown in (Table 2). Systolic blood pressure, fasting blood sugar, serum triglycerides, renal functions, WC and WHR are all significantly correlated with ACR.

\begin{tabular}{|c|c|c|}
\hline \multirow{2}{*}{} & \multicolumn{2}{|c|}{ Albumin/creatinine } \\
\cline { 2 - 3 } & r & P-value \\
\hline AGE & -0.021 & 0.840 \\
\hline DBP & 0.757 & $<0.001^{*}$ \\
\hline Blood urea nitrogen & 0.004 & 0.973 \\
\hline Serum creatinine & 0.833 & $<0.001^{*}$ \\
\hline Fasting blood sugar & 0.868 & $<0.001^{*}$ \\
\hline Serum triglycerides & 0.468 & $<0.001^{*}$ \\
\hline Total cholesterol & 0.073 & 0.482 \\
\hline LDL & -0.127 & 0.222 \\
\hline HDL & -0.084 & 0.422 \\
\hline WC & 0.698 & $<0.001^{*}$ \\
\hline HC & 0.156 & 0.125 \\
\hline WHR & 0.463 & $<0.001^{*}$ \\
\hline BMI & 0.146 & 0.152 \\
\hline
\end{tabular}

Systolic blood pressure (SBP), Diastolic blood pressure (DBP), Waist circumference (WC) in cm, Hip circumference (HC) in cm, Waist hip ratio (WHR), Body mass index (BMI)

Table 2: Relation between age, anthropometric measurements, blood pressure, laboratory measurements and micro-albuminuria among subjects

(Table 3) shows a significant relation between diabetes, hypertension, renal disease, ischemic heart disease and ACR.

\begin{tabular}{|c|c|c|c|c|}
\hline \multirow{4}{*}{ DM } & \multirow{4}{*}{$\begin{array}{c}\text { Negative } \\
\text { Positive }\end{array}$} & \multirow{2}{*}{$\begin{array}{c}\text { Albumin/creatinine } \\
\text { Mean } \pm \text { SD }\end{array}$} & \multicolumn{2}{|c|}{ T-test } \\
\hline & & & \multirow{3}{*}{$\begin{array}{c}\mathbf{t} \\
-7.120\end{array}$} & \multirow{3}{*}{$\frac{\text { P-value }}{0.000^{\star}}$} \\
\hline & & $3.243 \pm 0.435$ & & \\
\hline & & $4.921 \pm 1.710$ & & \\
\hline \multirow[t]{2}{*}{ HTN } & Negative & $3.536 \pm 0.951$ & \multirow[t]{2}{*}{-3.201} & \multirow[t]{2}{*}{$0.002^{*}$} \\
\hline & Positive & $4.411 \pm 1.696$ & & \\
\hline \multirow[t]{2}{*}{ COPD } & Negative & $4.162 \pm 1.445$ & \multirow[t]{2}{*}{1.783} & \multirow[t]{2}{*}{0.078} \\
\hline & Positive & $3.643 \pm 1.363$ & & \\
\hline \multirow[t]{2}{*}{ ISHD } & Negative & $1.276 \pm 1.659$ & \multirow[t]{2}{*}{2.217} & \multirow[t]{2}{*}{$0.029^{*}$} \\
\hline & Positive & $.675 \pm 0.507$ & & \\
\hline \multirow[t]{2}{*}{$\mathrm{CHF}$} & Negative & $4.019 \pm 1.471$ & \multirow[t]{2}{*}{0.860} & \multirow[t]{2}{*}{0.392} \\
\hline & Positive & $3.683 \pm 1.195$ & & \\
\hline \multirow[t]{2}{*}{ CLD } & Negative & $3.978 \pm 1.505$ & \multirow[t]{2}{*}{0.256} & \multirow[t]{2}{*}{0.798} \\
\hline & Positive & $3.865 \pm 0.691$ & & \\
\hline \multirow[t]{2}{*}{ Renal disease } & Negative & $3.547 \pm 0.652$ & \multirow[t]{2}{*}{-4.970} & \multirow[t]{2}{*}{$0.000^{*}$} \\
\hline & Positive & $4.940 \pm 2.137$ & & \\
\hline \multirow[t]{2}{*}{ OLD.CVS } & Negative & $4.002 \pm 1.542$ & \multirow[t]{2}{*}{0.600} & \multirow[t]{2}{*}{0.550} \\
\hline & Positive & $3.768 \pm 0.541$ & & \\
\hline \multirow[t]{2}{*}{ DEMENTIA } & Negative & $1.038 \pm 1.364$ & \multirow[t]{2}{*}{0.42} & \multirow[t]{2}{*}{0.676} \\
\hline & Positive & $0.750 \pm 0.289$ & & \\
\hline
\end{tabular}

Diabetes mellitus (DM), Hypertension (HTN), Chronic obstructive pulmonary disease (COPD), Ischemic heart disease (ISHD), Congestive heart failure (CHF), Chronic liver disease (CLD), Cerebrovascular disease (CVS)

Table 3: Relation between co-morbidities among subjects and albumin/creatinine ratio 
Sex difference showed a significant correlation with MA as shown in (Table 4).

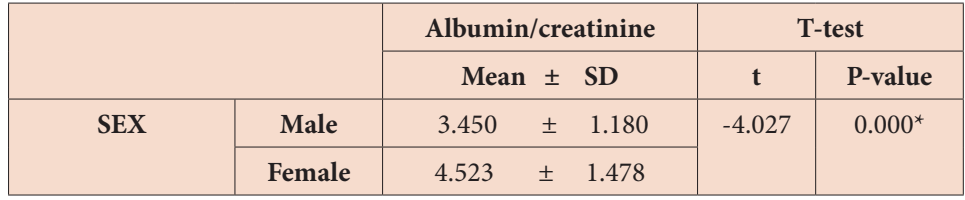

Table 4: Relation between gender and albumin/creatinine ratio

Significant clinical variables (Diabetes Milletus, Hypertension, renal disease, ischemic heart disease, sex, systolic blood pressure, fasting blood sugar, serum triglycerides, renal functions, WC and WHR) were all entered in a multivariate stepwise regression model which showed in the final step of analysis that abdominal obesity as presented by WHR is the most correlated variable with presence of micro-albuminuria (Table 5).

\begin{tabular}{|c|c|c|c|c|c|c|c|}
\hline \multirow{2}{*}{\multicolumn{2}{|c|}{ Stepwise regression }} & \multicolumn{2}{|c|}{$\begin{array}{l}\text { Unstandardized } \\
\text { Coefficients }\end{array}$} & \multirow{2}{*}{$\begin{array}{c}\text { Standardized } \\
\text { Coefficients } \\
\text { Beta } \\
\end{array}$} & \multicolumn{2}{|c|}{ T-test } & \multirow[b]{2}{*}{$\mathbf{R}^{2}$} \\
\hline & & B & $\begin{array}{l}\text { Std. } \\
\text { Error }\end{array}$ & & $\mathbf{t}$ & P-value & \\
\hline \multirow{5}{*}{ Final step 5} & (Constant) & 5.273 & 1.061 & & 4.969 & 0.000 & \multirow{2}{*}{$99.04 \%$} \\
\hline & WHR & 0.856 & 0.033 & 0.819 & 25.564 & 0.000 & \\
\hline & FBS & 0.005 & 0.001 & 0.188 & 3.928 & 0.000 & \\
\hline & SBP & 0.026 & 0.006 & 0.168 & 4.457 & 0.000 & \\
\hline & TG & 0.002 & 0.001 & 0.045 & 2.246 & 0.031 & \\
\hline
\end{tabular}

FBS (fasting blood sugar), TG (serum triglycerides), Systolic blood pressure (SBP), Waist hip ratio (WHR) Table 5: The final step of multivariate stepwise regression model for significant clinical variables

\section{Discussion}

The relation between abdominal obesity and micro-albuminuria has been investigated in this cross sectional study. Mean age of participants was $74.96 \pm 5.603$ years, males represented $52 \%$ of sample and females represented $48 \%$.

As per our results central obesity as measured by WHR has been significantly associated with MA among subjects in the whole sample, also there has been a significant relation between MA, some comorbidities and some laboratorial measurements, meanwhile on multivariate regression analysis, abdominal obesity as measured by WHR was the most significantly correlated variable with MA.

Reviewing literature, several studies suggested that abdominal obesity is independently associated with MA [22-25], also some studies described the correlations among central obesity, insulin resistance and micro-albuminuria, an early sign of kidney disease and an important risk factor for overt nephropathy suggesting that abdominal obesity, may be independently associated with micro-albuminuria [26-28]. On the contrary, other studies showed that abdominal obesity is not related to the albuminuria level $[29,30]$. The latter studies may have been biased by factors such as a small sample size. The association between abdominal obesity and MA is attributed to elevated insulin levels, peripheral tissue resistance to the insulin-sensitizing action of leptin and increased macrophage infiltration in fat tissues with concomitant release of pro-inflammatory cytokines $[15,16]$, which in turn decreases the functional integrity of the renal endothelial wall and lead to micro-albuminuria [9].

In the current study, Diabetes was among the co-morbidities that showed significant relation with MA among studied subjects, which agreed with results of number of studies conducted on patients with diabetes [31-33] reporting micro-albuminuria as an independent predictor of progressive renal disease.

Although Diabetes was significantly related to MA in this study, WHR was the most significantly correlated variable with MA, which agreed with studies signifying the role of anthropometric measurements in the identification of non-diabetic individuals at risk of developing MA [34] and also, agreed with several studies reporting that endothelial dysfunction precedes and predicts the onset of micro-albuminuria in individuals with and without diabetes $[35,36]$.

Hypertension was also one of the co-morbidities that showed significant relation with MA among studied subjects, which agreed with results of number of studies reporting MA as an independent predictor of progressive renal disease in patients with hypertension [37].

On the other hand, Scaglione et al reported that both in normotensive and hypertensive individuals, only those with centrally located obesity but not those with peripheral obesity had elevated urinary albumin excretion rates [38]. Also Chang et al study showed that systolic blood pressure was an independent predictors of MA in Asian normotensive, euglycemic male population, which signifies the importance of observing systolic blood pressure even in men without hypertension and diabetes [39]. 
In the current study, a significant relation between MA and ischemic heart disease was found which agreed with studies reporting proteinuria as a risk factor for cardiovascular and total mortality [4,5].

The relation between renal disease and presence of MA is well-established and is evident in our study as well as other studies which reported that micro-albuminuria is associated with renal functional abnormalities in non-diabetic subjects [8] and is a predictor of nephropathy in diabetic patients [7].

WC and WHR (measures of abdominal obesity) showed a significant association with MA in the current study whereas BMI had not, supporting that body mass index does not account for the wide variations in body fat distribution, and has limitations in prediction of intra-abdominal fat accumulation [12]. Of the three measurements, only the waist-hip ratio takes account of the differences in body structure. Waist hip ratio is reported to be a better predictor of cardiovascular disease than waist circumference [14]. If obesity is defined using WHR, the proportion of people categorized as at risk of heart attack worldwide increases threefold $[40]$.

On stepwise regression analysis, significant relation between WHR, Systolic blood pressure, fasting blood sugar, serum triglycerides level and MA among subjects is being observed, suggesting a possible association between metabolic syndrome and MA and that agreed with the Third National Health and Nutrition Examination Survey (NHANES III: 1988-1994) which recommended considering MA a component of the metabolic syndrome [25]. The precise pathogenetic basis of MA in metabolic syndrome is not known; it is, however, possible that microalbuminuria in metabolic syndrome reflects renin-angiotensin system activation and resultant oxidant stress and inflammation. Several investigators have shown that hypertension, dyslipidemia, and insulin resistance are associated with renin-angiotensin system activation and generation of large amounts of angiotensin II [41,42].

We did not find a significant relation between age and MA, which may be attributed to the narrow range of age in our study unlike the results of that cross sectional study conducted on Korean men in which age ranged from 20-78 years and found a significant relation with MA [39]. On the other hand, sex difference showed a significant correlation with MA in the present study and that agreed with what was reported by Bhaktha et al [9].

\section{Conclusion}

Thus we can conclude through the present study results that Abdominal obesity is strongly associated with micro-albuminuria in Egyptian elderly which signifies the importance of weight control to prevent micro-albuminuria and renal damage.

\section{Study limitations}

Our study has some limitations. First, we undertook only a single blood pressure measurement that does not take into account day-to-day variability and white coat blood pressure effect. Second, lack of data regarding dietary habits of participants as diet represent an important risk factor for kidney diseases.

\section{Acknowledgement}

We are grateful to all residents, staff and participating patients. Informed consent was taken from elderly participating in this study; also an approval was taken from the head of participating departments. The study methodology was reviewed and approved by the Research Review Board of the Geriatrics and Gerontology Department, Faculty of medicine, Ain Shams University, cairo, Egypt.

\section{References}

1. Ibrahim MM, Appel LJ, Rizk HH, Helmy S, Mosley J, et al. (2001) Cardiovascular risk factors in normotensive and hypertensive Egyptians. J Hypertens 19: 1933-40.

2. Chandra A, Biersmith M, Tolouian R (2014) Obesity and kidney protection. J Nephropathol 3: 91-7.

3. Iseki K, Iseki C, Ikemiya Y, Fukiyama K (1996) Risk of developing end-stage renal disease in a cohort of mass screening. Kidney Int 49: 800-5.

4. Culleton BF, Larson MG, Parfrey PS, Kannel WB, Levy D (2000) Proteinuria as a risk factor for cardiovascular disease and mortality in older people: a prospective study. Am J Med 109: 1-8.

5. Grimm RH Jr, Svendsen KH, Kasiske B, Keane WF, Wahi MM (1997) Proteinuria is a risk factor for mortality over 10 years of follow-up. MRFIT Research Group. Multiple Risk Factor Intervention Trial. Kidney Int Suppl 63: S10-4.

6. American Diabetes Association (2005) Standards of medical care in diabetes. Diabetes Care 1: S4-S36.

7. Mogensen CE (1984) Microalbuminuria predicts clinical proteinuria and early mortality in maturity-onset diabetes. N Engl J Med 310: $356-60$.

8. Pinto-Sietsma SJ, Janssen WM, Hillege HL, Navis G, De Zeeuw D, et al. (2000) Urinary albumin excretion is associated with renal functional abnormalities in a nondiabetic population. J Am Soc Nephrol 11: 1882-8.

9. Bhaktha G, Nayak S, D’Souza NDR, Shantaram M (2011) Micro-albuminuria (MAU) and its Relationship with Anthropometric Variables In Type 2 Diabetic And Non Diabetic Females of Dakshina Kannada District in Indian Population. Int J Pharma Biologic Sci 1: 341-6.

10. Lemieux S, Prud'homme D, Bouchard C, Tremblay A, Després JP (1996) A single threshold value of waist girth identifies normal-weight and overweight subjects with excess visceral adipose tissue. Am J Clin Nutr 64: 685-93. 
11. Molarius A, Seidell JC (1998) Selection of anthropometric indicators for classification of abdominal fatness--a critical review. Int J Obes Relat Metab Disord 22: 719-27.

12. Deurenberg P, Yap M (1999) The assessment of obesity: methods for measuring body fat and global prevalence of obesity. Baillieres Best Pract Res Clin Endocrinol Metab 13: 1-11.

13. Price GM, Uauy R, Breeze E, Bulpitt CJ, Fletcher AE (2006) Weight, shape, and mortality risk in older persons: elevated waist-hip ratio, not high body mass index, is associated with a greater risk of death. Am J Clin Nutr 84: 449-60.

14. Mørkedal B, Romundstad PR, Vatten LJ (2011) Informativeness of indices of blood pressure, obesity and serum lipids in relation to ischaemic heart disease mortality: the HUNT-II study. Eur J Epidemiol 26: 457-61.

15. McGarry JD (2002) Banting lecture 2001: dysregulation of fatty acid metabolism in the etiology of type 2 diabetes. Diabetes 51: 7-18.

16. Bagby SP (2004) Obesity-Initiated Metabolic Syndrome and the Kidney: A Recipe for Chronic Kidney Disease? J Am Soc Nephrol 5: $2775-91$.

17. World Health Organization (WHO) "STEPwise approach to surveillance (STEPS)".

18. World Health Organization (2008) "Waist Circumference and Waist-Hip Ratio, Report of a WHO Expert Consultation”, Geneva.

19. Bakker AJ (1999) Detection of microalbuminuria. Receiver operating characteristic curve analysis favors albumin-to-creatinine ratio over albumin concentration. Diabetes Care 22: 307-13.

20. UK Renal Association (2005) Proteinuria, UK.

21. NICE Clinical Guideline (2008) Chronic kidney disease, UK.

22. Knight EL, Kramer HM, Curhan GC (2003) High-normal blood pressure and micro-albuminuria. Am J Kidney Dis 41: 588-95.

23. Mulyadi L, Stevens C, Munro S, Lingard J, Bermingham M (2001) Body fat distribution and total body fat as risk factors for micro-albuminuria in the obese. Ann Nutr Metab 45: 67-71.

24. Rosenbaum P, Gimeno SG, Sanudo A, Franco LJ, Ferreira SR, et al. (2004) Independent impact of glycemia and blood pressure in albuminuria on high-risk subjects for metabolic syndrome. Clin Nephrol 61: 369-76.

25. Palaniappan L, Carnethon M, Fortmann SP (2003) Association between microalbuminuria and the metabolic syndrome: NHANES III. Am J Hypertens 16: 952-8.

26. Sibley SD, Thomas W, de Boer I, Brunzell JD, Steffes MW (2006) Gender and elevated albumin excretion in the Diabetes Control and Complications Trial/ Epidemiology of Diabetes Interventions and Complications (DCCT/EDIC) cohort: role of central obesity. Am J Kidney Dis 47: 223-32.

27. Orchard TJ, Chang YF, Ferrell RE, Petro N, Ellis DE (2002) Nephropathy in type 1 diabetes: A manifestation of insulin resistance and multiple genetic susceptibilities? Further evidence from the Pittsburgh Epidemiology of Diabetes Complication Study. Kidney Int 62: 963-70.

28. Chaturvedi N, Bandinelli S, Mangili R, Penno G, Rottiers RE, et al. (2001) Microalbuminuria in type 1 diabetes: Rates, risk factors and glycemic threshold. Kidney Int 60: 219-27.

29. Hoffmann IS, Jimenez E, Cubeddu LX (2001) Urinary albumin excretion in lean, overweight and obese glucose tolerant individuals: its relationship with dyslipidaemia, hyperinsulinaemia and blood pressure. J Hum Hypertens 15: 407-12.

30. Nielsen S, Jensen MD (1999) Relationship between urinary albumin excretion, body composition, and hyperinsulinemia in normotensive glucose-tolerant adults. Diabetes Care 22: 1728-33.

31. Dinneen SF, Gerstein HC (1997) The association of microalbuminuria and mortality in non-insulin-dependent diabetes mellitus. A systematic overview of the literature. Arch Intern Med 157: 1413-8.

32. Gerstein HC, Mann JF, Yi Q, Zinman B, Dinneen SF, et al. (2001) Albuminuria and risk of cardiovascular events, death, and heart failure in diabetic and non diabetic individuals. JAMA 286: 421-6.

33. Allen KV, Walker JD (2003) Microalbuminuria and mortality in long-duration type 1 diabetes. Diabetes Care 26: $2389-91$.

34. Bonnet F, Marre M, Halimi JM, Stengel B, Lange C, et al. (2006) Waist circumference and the metabolic syndrome predict the development of elevated albuminuria in non-diabetic subjects: the DESIR Study. J Hypertens 24: 1157-63.

35. DeFronzo RA, Ferrannini E, Keen H, Zimmet P (2004) Endothelial function and dysfunction. In: International Textbook of Diabetes Mellitus (3rd edn) Wiley Publisher, USA.

36. Stehouwer CD (2004) Endothelial dysfunction in diabetic nephropathy: state of the art and potential significance for non-diabetic renal disease. Nephrol Dial Transplant 19: 778-81.

37. Wachtell K, Ibsen H, Olsen MH, Borch-Johnsen K, Lindholm LH, et al. (2003) Albuminuria and cardiovascular risk in hypertensive patients with left ventricular hypertrophy: the LIFE study. Ann Intern Med 139: 901-6.

38. Scaglione R, Ganguzza A, Corrao S, Parrinello G, Merlino G (1995) Central obesity and hypertension: pathophysiologic role of renal haemodynamics and function. Int J Obes Relat Metab Disord 19: 403-9.

39. Chang Y, Yoo T, Ryu S, Huh BY, Cho BL, et al. (2006) Abdominal obesity, systolic blood pressure, and microalbuminuria in normotensive and euglycemic Korean men. Int J Obes 30: 800-4.

40. Yusuf S, Hawken S, Ounpuu S, Bautista L, Franzosi MG, et al. (2005) Obesity and the risk of myocardial infarction in 27,000 participants from 52 countries: a case-control study. Lancet 366: 1640-9.

41. Dzau VJ, Safar ME (1988) Large conduit arteries in hypertension: role of the vascular renin-angiotensin system. Circulation 77: $947-54$.

42. Shinozaki K, Ayajiki K, Nishio Y, Sugaya T, Kashiwagi A (2004). Evidence for a causal role of the renin-angiotensin system in vascular dysfunction associated with insulin resistance. Hypertension 43: 255-62. 


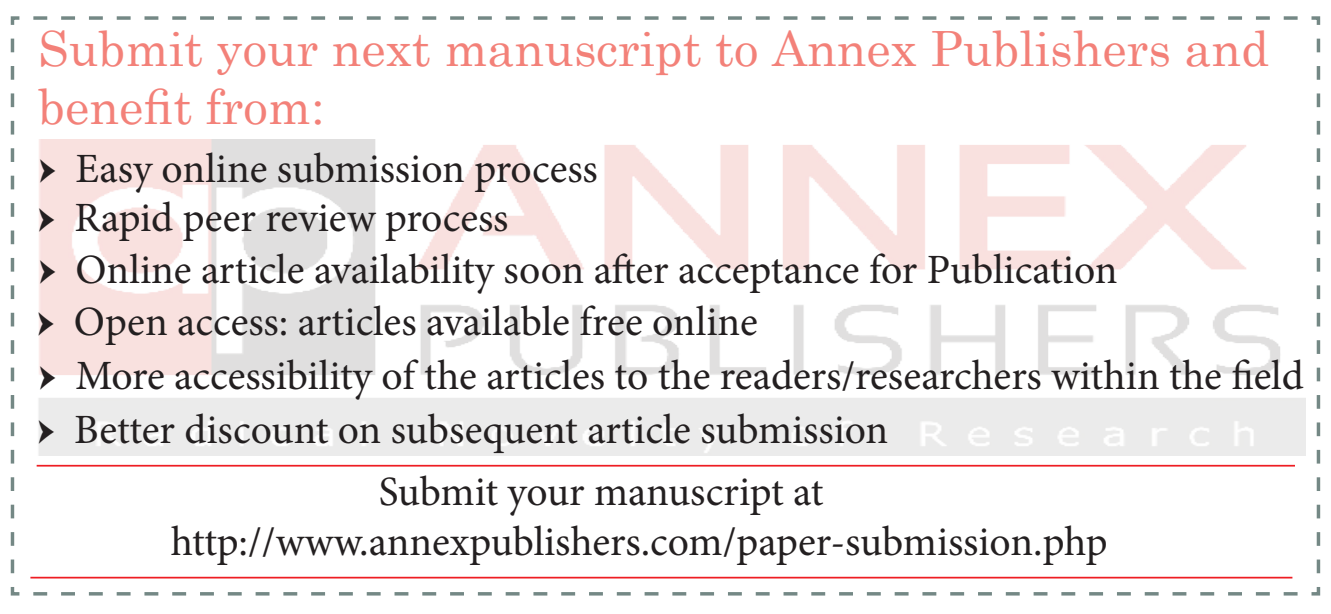

